\title{
Do Korean Doctors Think a Palliative Consultation Team Would Be Helpful to Their Terminal Cancer Patients?
}

Hye-Young Shim, PhD'1
Yoon Jung Chang, MD, PhD²
Kiu-Sang Kawk, MA²
Tran Thi Xuan Mai, BS²
Jin Young Choi, PhD²
Eun Mi Ahn, MD, MA²
Hyun Jung Jho, MD, MA²
So-Jung Park, MD, BS²

${ }^{1}$ Department of Preventive Medicine, Eulji University School of Medicine, Daejeon, ${ }^{2}$ Hospice \& Palliative Care Branch, National Cancer Control Institute, National Cancer Center, Goyang, Korea

\author{
Correspondence: Yoon Jung Chang, MD, PhD \\ Hospice and Palliative Care Branch, \\ National Cancer Control Institute, \\ National Cancer Center, 323 Ilsan-ro, \\ Ilsandong-gu, Goyang 10408, Korea \\ Tel : 82-31-920-2190 \\ Fax: 82-31-920-2199 \\ E-mail: eunice.ncc@gmail.com \\ Received December 21, 2015 \\ Accepted July 22, 2016 \\ Published Online August 10, 2016
}

\begin{abstract}
Purpose
Hospice and palliative care services (HPC) are not commonly utilized in Korea; however, palliative care teams (PCTs) have been found to be effective at addressing the shortcomings in HPC. In this study, we attempted to outline unmet palliative care needs of terminal cancer patients and the potential benefits of PCTs as perceived by doctors in Korea.
\end{abstract}

\section{Materials and Methods}

We surveyed 474 doctors at 10 cancer-related academic conferences from June to November 2014 with a self-report questionnaire to assess their perceptions of end-of-life care needs and the expected effects of PCTs on caring for terminal cancer patients. Among those surveyed, 440 respondents who completed the entire questionnaire were analyzed.

\section{Results}

In all domains, fewer participants reported satisfaction with palliative care services than those reporting needs $(p<0.001)$. The surveyed participants also reported difficulties with a shortage of time for treatment, psychological burden, lack of knowledge regarding hospice care, lengths of stay, and palliative ward availability. Multivariate logistic regression analysis revealed that female doctors (odds ratio [OR], 2.672; 95\% confidence interval [Cl], 1.035 to 6.892), doctors who agreed that referring my patients to a HPC means I must give up on my patient (OR, 3.075; 95\% Cl, 1.324 to 7.127 ), and doctors who had no experience with HPC education (OR, 3.337; 95\% $\mathrm{Cl}, 1.600$ to 7.125$)$ were associated with higher expected effectiveness of PCT activities.

\section{Conclusion}

The PCT activities were expected to fill the doctor's perceived unmet HPC needs of terminal cancer patients and difficulties in communications.

Key words

Hospices, Palliative care, Referral and consultation, Neoplasms

\section{Introduction}

Palliative care is designed to relieve suffering and improve the quality of life of patients with life-threatening illnesses and their caregivers [1]. In 2014, the World Health Organization (WHO) declared strengthening palliative care as a component of integrated treatment throughout the life course [1]. Palliative care teams (PCTs) have been proposed as a recently developed model to improve early access to hospice and palliative care (HPC), offering multi-disciplinary advisory consultation services through specialized teams of doctors, nurses, and social workers [2]. PCTs have gradually spread throughout the United States [2], United Kingdom [3], Canada [4], Australia [5], German [6], Spain [7], Japan [8], and Taiwan [9], and their effectiveness has been explored. Studies suggest that PCTs are effective at addressing the shortcomings in HPC [10], improving symptom management [11], providing insights into cancer patients and their diseases [12], clarifying the goals of end-of-life (EOL) care 
[13], offering better psychosocial and spiritual support [13], and helping with discharge planning [2,13]. Many studies have also shown that PCTs increase patient and family satisfaction [14], improve quality of life [15], reduce length of stays in intensive care units [15], and decrease hospital costs [14].

In Korea, only $13.8 \%$ of all terminal cancer patients who died in 2014 utilized a hospice and palliative care unit (PCU) [16]. Since 2005, the Ministry of Health and Welfare of Korea has financially supported 64 hospitals (1,047 beds) designated to offer HPC [16]. However, the overall infrastructure and utilization of HPC in Korea has proven insufficient. According to previous studies, lack of awareness with HPC, denial of terminal illness, and refusal of medical referral to HPC from patients and their families have hindered the utilization of HPC in Korea [17-20]. Korean doctors have also expressed difficulties in communication with patients and their family members concerning terminal illness, the implications of offering life-sustaining treatments to terminal patients, and recommendation of HPC upon impending death [17-19]. Nevertheless, studies have shown that late referral to palliative care hinders acceptance of death among terminal cancer patients and their family members $[21,22]$. As a mediator between medical staff and patients [23], PCTs can shorten the referral time to HPC, allowing more time to address the complexity of problems associated with caring for terminally-ill patients [24]. Indeed, the Mayo Clinic palliative team reported that building a rapport with a patient and their family via a palliative approach reduced the likelihood of delayed referral, as well as health care-related costs [25].

Even though recommendations from a doctor are important factors associated with hospice use [26], few studies have attempted to investigate doctors' perceptions of terminal cancer patients' needs, attitudes toward HPC, and expectations of PCT. Therefore, this study was conducted to identify needs and unmet needs in EOL care for terminal cancer patients, and to outline the expected impact of PCTs as perceived by doctors in Korea.

\section{Materials and Methods}

\section{Study design and population}

To identify HPC needs for terminal cancer patients and expectations regarding PCTs among Korean doctors, we conducted a survey of doctors at 10 cancer-related medical academic conferences from June to November; namely, the Korean Association for the Study of the Liver, Korean Cancer
Association, Korean Association for the Study of Lung Cancer, the Korean Society for Head and Neck Oncology, Korean Breast Cancer Society, the Korean Brain Tumor Society, the Laparoscopy Society, the Korean Spinal Neurosurgery Society, Korean Clinic Cancer Prevention Society, and the Korean Bone and Joint Tumor Society. Subjects included in the survey comprised interns, residents, and professional members of the listed academic societies. This study was approved by the institutional review board of the National Cancer Center in Korea, all potential participants provided informed consent before participating in the survey and trained surveyors assisted the doctors with a self-report questionnaire. Among 1,399 doctors that attended the 10 conferences, 474 participated in the survey (response rate, $33.7 \%$ ), and 440 doctors completed the entire questionnaire.

\section{Questionnaire}

We defined the consultation PCT as follows and specified it in the questionnaire. "The consultation PCT means that a multidisciplinary team (doctors, nurses, social workers, etc.) visits patients who are under medical treatment in a general unit, not the PCU, and provides the palliative care to them. It does not change the doctor responsible for the patient; rather, the PCT provides services such as support with symptom control, psychological, social and spiritual care, EOL care, bereavement care, communication (goals of EOL, advance directives), and linkage to hospice and PCUs (or special hospitals)."

The administered questionnaire was designed to assess doctor's perceived terminal cancer patient's needs and unmet needs of EOL care and expected effects on PCTs. The questionnaire consisted of five parts: (1) doctor's perceived terminal cancer patients and family's needs and unmet needs of end-of life care (16 questions), (2) doctor's difficulties associated with EOL care (seven questions), (3) attitudes toward HPC (seven questions), (4) expected effectiveness of PCT activities (16 questions), and (5) clinical experiences and demographics (14 questions).

The following demographic characteristics of the respondents were recorded: sex, age, affiliation with a designated PCU, percentage of terminal cancer patients treated, specialty, hospital type, education regarding hospice care, and willingness to seek PCT consultation. Patient-related aspects of EOL care included control of pain and physical symptoms, psychological care for the patient and their family, communication, socio-economic care, spiritual care, advanced care planning, and care for bereaved family members. Need for and satisfaction with each of these aspects were assessed on a four-point Likert scale. Physician-related aspects of PCTs consisted of lack of time for care, psychological burden, lack of experience or knowledge, and conflicts with hospital 
guidelines regarding admission indications. Difficulties with and the expected benefits of PCTs were assessed on a fourpoint Likert scale. We also surveyed the attitudes of doctors toward HPC based on five items, referring my patient to HPC means giving up on my patient, referring my patient to HPC causes them to lose hope, I only transfer my patient to HPC at the time of impending death, care for the dying patient is my obligation, HPC is a worthwhile activity.

\section{Statistical analysis}

Needs perceived by doctors in EOL care for terminal cancer patients and the expected effectiveness of PCTs were analyzed by ANOVA. The reasons for doctors' difficulties with EOL care and the expected effectiveness of PCTs were analyzed by t-tests. Doctors' attitudes toward HPC were analyzed as clusters of "expected effectiveness of PCT activities" using two-way chi-squared tests. The "expected effectiveness of PCT activities" was classified according to "satisfaction with EOL care" and "expected effectiveness of PCT activities on EOL care." To determine factors potentially affecting the doctors' expectations of PCT activities, we also carried out multivariate logistic regression analysis. Sociodemographic factors (sex, age) were evaluated by covariate analysis along with doctor's attitudes toward HPC, such as grasping pending death, loss of hope, belief that it is a worthwhile activity, hospital type, belief that referring my patients to a PCU means I must give up on them, hospice education, percentage of terminal patients treated, affiliation with a designated PCU, specialty, and PCT expectations, as dependent variables. All statistical analyses were conducted using the STATA ver. 12 (STATA Corp., College Station, TX). Statistical significance was set at $\mathrm{p}<0.05$, and all $\mathrm{p}$-values were twosided.

\section{Results}

\section{General characteristics}

Of the 440 doctors who completed the survey, 341 were male $(77.5 \%)$ and 99 were female $(22.5 \%)$, with a mean age of 40.7 years. Eighty of the doctors were affiliated with a designated PCU (18.2\%), 224 (50.9\%) were surgeons, 258 (59.6\%) were employed at a tertiary hospital, and $71(16.1 \%)$ had undergone HPC education (Table 1).

\section{Perceived needs and satisfaction with EOL care to termi- nal cancer patients and their family and expected effective- ness of PCTs activities on EOL care}

Doctors expressed that EOL care was most needed to "control pain and physical symptoms" among terminal cancer patients $(\mathrm{p}<0.001)$. Most of the doctors were unsatisfied,

Table 1. Demographic characteristics

\begin{tabular}{|c|c|}
\hline Variable & No. $(\%)(n=440)$ \\
\hline \multicolumn{2}{|l|}{ Sex } \\
\hline Male & $341(77.5)$ \\
\hline Female & $99(22.5)$ \\
\hline \multicolumn{2}{|l|}{ Age (yr) } \\
\hline Mean \pm SD & $40.7 \pm 8.8$ \\
\hline$<30$ & $38(8.6)$ \\
\hline $30-39$ & $218(49.6)$ \\
\hline$\geq 40$ & $184(41.8)$ \\
\hline \multicolumn{2}{|c|}{ Affiliated with a designated PCU } \\
\hline Yes & $80(18.2)$ \\
\hline No & $360(81.8)$ \\
\hline \multicolumn{2}{|c|}{$\begin{array}{l}\text { Proportion of terminal cancer patients } \\
\text { among one's patients }(\%)\end{array}$} \\
\hline None & $41(9.1)$ \\
\hline $1-9$ & $193(44.0)$ \\
\hline $10-19$ & $85(19.4)$ \\
\hline $20-29$ & $45(10.4)$ \\
\hline$\geq 30$ & $75(17.1)$ \\
\hline \multicolumn{2}{|l|}{ Specialty } \\
\hline Hemato-oncology & $65(14.8)$ \\
\hline Other internal medicine & $89(20.2)$ \\
\hline Surgery & $224(50.9)$ \\
\hline Radiotherapy & $46(10.5)$ \\
\hline Miscellaneous & $16(3.6)$ \\
\hline \multicolumn{2}{|l|}{ Hospital type } \\
\hline Tertiary hospital & $258(59.6)$ \\
\hline Secondary hospital & $112(25.9)$ \\
\hline General hospital & $6(1.4)$ \\
\hline Clinic & $1(0.2)$ \\
\hline Long-term care hospital & $1(0.2)$ \\
\hline Others & $55(12.7)$ \\
\hline \multicolumn{2}{|l|}{$\begin{array}{l}\text { Experience of hospice and } \\
\text { palliative care education }\end{array}$} \\
\hline Yes & 71 (16.1) \\
\hline No & 369 (83.9) \\
\hline \multicolumn{2}{|l|}{$\begin{array}{l}\text { Willingness to consult with } \\
\text { a palliative care team }\end{array}$} \\
\hline Yes & $39(8.9)$ \\
\hline No & 401 (91.1) \\
\hline
\end{tabular}

SD, standard deviation; PCU, hospice and palliative care unit. 
Table 2. Doctor's perceived needs and satisfaction with EOL care to terminal cancer patients and expected effectiveness of PCTs activities

\begin{tabular}{|c|c|c|c|c|}
\hline & $\begin{array}{l}\text { Needs of EOL care } \\
\text { by terminal cancer } \\
\text { patients and } \\
\text { their family }\end{array}$ & $\begin{array}{l}\text { Satisfaction with } \\
\text { EOL care to terminal } \\
\text { cancer patients } \\
\text { and their family }\end{array}$ & $\begin{array}{c}\text { Expected } \\
\text { effectiveness of } \\
\text { PCTs activities } \\
\text { on EOL care }\end{array}$ & p-value \\
\hline $\begin{array}{l}\text { Control of pain and } \\
\text { physical symptoms }\end{array}$ & $4.725 \pm 0.535^{\mathrm{a}}$ & $3.690 \pm 0.656^{\mathrm{b}}$ & $4.063 \pm 0.718^{c}$ & $<0.001$ \\
\hline $\begin{array}{l}\text { Psychological care for } \\
\text { the patient and their family }\end{array}$ & $4.491 \pm 0.619^{a}$ & $3.007 \pm 0.822^{b}$ & $4.293 \pm 0.612^{c}$ & $<0.001$ \\
\hline Communication & $4.427 \pm 0.618^{\mathrm{a}}$ & $3.334 \pm 0.760^{\mathrm{b}}$ & $4.152 \pm 0.693^{c}$ & $<0.001$ \\
\hline Socio-economic care & $4.252 \pm 0.706^{\mathrm{a}}$ & $2.670 \pm 0.861^{b}$ & $3.840 \pm 0.820^{c}$ & $<0.001$ \\
\hline Spiritual care & $3.814 \pm 0.849^{\mathrm{a}}$ & $2.500 \pm 0.961^{b}$ & $3.866 \pm 0.853^{\mathrm{a}}$ & $<0.001$ \\
\hline Care for dying patients & $4.084 \pm 0.760^{\mathrm{a}}$ & $2.670 \pm 0.963^{b}$ & $4.130 \pm 0.756^{\mathrm{a}}$ & $<0.001$ \\
\hline Advanced care planning & $4.139 \pm 0.683^{\mathrm{a}}$ & $2.964 \pm 0.829^{b}$ & $3.879 \pm 0.785^{c}$ & $<0.001$ \\
\hline Care for the bereaved & $3.723 \pm 0.842^{\mathrm{a}}$ & $2.220 \pm 0.975^{b}$ & $3.878 \pm 0.850^{c}$ & $<0.001$ \\
\hline
\end{tabular}

Values are presented as mean \pm standard deviation. Scale: 1 , not very much; 2, not much; 3, somewhat; 4, much; 5 , very much. Values within a row with different superscripts $(\mathrm{a}-\mathrm{c})$ are different $(\mathrm{p}<0.05$; one-way ANOVA followed by Bonferroni post hoc). p-values were determined by ANOVA. EOL, end-of-life; PCT, palliative care team.

Table 3. The reasons for doctor's difficulties with EOL care to terminal cancer patients and their expected effectiveness of PCT activities

\begin{tabular}{lcrr} 
Cause of doctor's difficulties with EOL care & $\begin{array}{c}\text { Difficulties in } \\
\text { EOL care }\end{array}$ & $\begin{array}{c}\text { Expected effectiveness } \\
\text { of PCT activities }\end{array}$ & p-value \\
\hline Lack of time for care & $3.700 \pm 0.411$ & $3.800 \pm 0.338$ & 0.061 \\
Psychological burden & $3.661 \pm 0.419$ & $3.893 \pm 0.355$ & $<0.001$ \\
Lack of experience or knowledge & $3.152 \pm 0.420$ & $4.014 \pm 0.327$ & $<0.001$ \\
Conflicts with hospital policy regarding discharge indications & $3.600 \pm 0.408$ & $3.816 \pm 0.341$ & $<0.001$ \\
\hline
\end{tabular}

Values are presented as mean \pm standard deviation. Scale: 1, not very much; 2, not much; 3, somewhat; 4, much; 5, very much. $\mathrm{p}$-value by $\mathrm{t}$ test. EOL, end-of-life; PCT, palliative care team.

especially with "social and economic care," "psychological care," and "care for the bereaved." Doctors expected that PCT activities would have positive effects on EOL care, especially in "spiritual care," "care for a dying patient," and "care for the bereaved." However, they expressed that "pain and symptom control," "psychologic care," "communication," and "social and economic care" in EOL care were still insufficient (Table 2).

\section{Reasons for difficulties in EOL care to terminal cancer patients and the expected effectiveness of PCT activities}

Doctors difficulties with EOL care stemmed from a "lack of time," "psychological burden," and "conflict with hospital policy" $(\mathrm{p}<0.001)$. However, they suggested that most of these difficulties could be overcome by PCTs (Table 3).

\section{Doctor's attitudes toward HPC}

Doctors who had positive attitudes toward HPC expected greater effectiveness for PCT activities $(\mathrm{p}=0.005)$. Doctors who had negative attitudes toward HPC did not expect PCT activities to be effective. Doctors who disagreed with their clinical obligation to "care for dying patients," but agreed with the value of EOL care expected greater effectiveness of PCT activities $(\mathrm{p}=0.005)$ (Table 4$)$. 
Table 4. Doctor's attitude toward HPC

\begin{tabular}{|c|c|c|c|c|}
\hline & Total & $\begin{array}{c}\text { No expected } \\
\text { effectiveness } \\
\text { of PCT activities } \\
(n=47,10.7 \%)\end{array}$ & $\begin{array}{c}\text { Expected } \\
\text { effectiveness } \\
\text { of PCT activities } \\
(n=392,89.3 \%)\end{array}$ & p-value \\
\hline \multicolumn{5}{|c|}{$\begin{array}{l}\text { Referring my patient to HPC means } \\
\text { "giving up on my patient" }\end{array}$} \\
\hline Agree & $44(10.0)$ & $14(31.8)$ & $30(68.2)$ & $<0.001$ \\
\hline Disagree & $396(90.0)$ & $33(8.3)$ & $363(91.7)$ & \\
\hline \multicolumn{5}{|c|}{ Referring my patient to HPC makes him lose hope } \\
\hline Agree & $75(17.0)$ & $18(24.0)$ & $57(76.0)$ & $<0.001$ \\
\hline Disagree & $365(83.0)$ & $29(7.9)$ & $336(92.1)$ & \\
\hline \multicolumn{5}{|c|}{$\begin{array}{l}\text { I only transfer my patient to HPC } \\
\text { at the time of impending death }\end{array}$} \\
\hline Agree & $89(20.3)$ & $17(19.1)$ & $72(80.9)$ & 0.004 \\
\hline Disagree & $351(79.7)$ & $30(8.5)$ & $321(91.5)$ & \\
\hline \multicolumn{5}{|c|}{ Care for a dying patient is my clinical obligation } \\
\hline Agree & $170(38.6)$ & $26(15.3)$ & $144(84.7)$ & 0.013 \\
\hline Disagree & $270(61.4)$ & $21(7.8)$ & 249 (92.2) & \\
\hline \multicolumn{5}{|c|}{$\begin{array}{l}\text { Care for terminal cancer patients and } \\
\text { family is a worthwhile activity }\end{array}$} \\
\hline Agree & $196(44.6)$ & 31 (15.8) & $165(84.2)$ & 0.002 \\
\hline Disagree & $243(55.4)$ & $16(6.6)$ & 227 (93.4) & \\
\hline
\end{tabular}

Values are presented as number (\%). HPC, hospice and palliative care; PCT, palliative care team.

Table 5. Multiple logistic regression model of factors associated with doctor's expected effectiveness of palliative care team activities

\begin{tabular}{|c|c|c|c|}
\hline & No. $(\%)$ & $\begin{array}{l}\text { Adjusted } \\
\text { odds ratio }\end{array}$ & $95 \% \mathrm{CI}$ \\
\hline \multicolumn{4}{|l|}{ Sex } \\
\hline Male & $341(77.5)$ & 1 & \\
\hline Female & $99(22.5)$ & 2.672 & $1.035-6.892$ \\
\hline \multicolumn{4}{|c|}{$\begin{array}{l}\text { Referring my patient to the hospice and } \\
\text { palliative care means "giving up on my patient" }\end{array}$} \\
\hline Agree & $44(10.0)$ & 1 & \\
\hline Disagree & $396(90.0)$ & 3.075 & 1.324-7.127 \\
\hline \multicolumn{4}{|c|}{ Experience with hospice and palliative care education } \\
\hline Yes & $71(16.1)$ & 1 & \\
\hline No & $369(83.9)$ & 3.337 & $1.600-7.125$ \\
\hline
\end{tabular}

Adjusted for attitudes associated with hospice and palliative care such as pending death, loss of hope, and worthwhile activity, hospital type, age, percentage of terminal cancer patients, designated hospice unit, specialty. CI, confidence interval. 


\section{Factors affecting expectations of PCTs}

Multivariate logistic regression analysis revealed that female doctors (odds ratio [OR], 2.672; 95\% confidence interval [CI], 1.035 to 6.892$)$, doctors who agreed that "referring my patients to a HPC" means I must give up on my patient (OR, 3.075; 95\% CI, 1.324 to 7.127), and doctors who had no experience with HPC education (OR, 3.337; 95\% CI, 1.600 to 7.125) were associated with higher expected effectiveness of PCT activities (Table 5).

\section{Discussion}

In this study, we outlined doctors' perceptions regarding the unmet EOL care needs of terminal cancer patients and the expected effectiveness of PCT activities. Our findings suggested that most doctors were frustrated with EOL care in areas of physical pain control, psychosocial care, communication, socioeconomic care, spiritual care, care for dying patients, bereavement care, after-discharge care, and longterm care services for terminally-ill cancer patients. Nevertheless, the surveyed doctors expected that adoption of PCTs would help improve services in these areas.

The participants in the present study expressed that they believed EOL care would likely improve if PCTs are adopted; however, doing so is not likely to satisfy all unmet needs. According to a study by Pantilat at al. [27], implementation of PCTs did not improve pain or depression and did not reduce symptom severity among chronic patients relative to routine care, although it did help patients overcome dyspnea and anxiety and improved their spiritual well-being. Rabow et al. [28] suggested that PCTs do not improve pain, depression, or quality of life among patients. Upon referral to a PCT, patients are generally assessed by a social worker with physician review, rather than direct examination by a physician, which could explain why primary care physicians tend not to follow PCT recommendations. Therefore, as the effectiveness of PCTs may differ among various clinical settings (e.g., payment systems, patient type [inpatients, outpatients, emergency room patients], and hospital protocols), we suggest the need for more strenuous assessment of the effectiveness of PCTs and identification of the potential limitations and obstacles to EOL care through PCTs to improve quality of life and palliative care services for terminal cancer patients.

PCTs are expected to have positive effects on care settings in which doctors themselves are required to provide palliative care services to their patients. Since the effects of and experiences with PCTs have mostly been studied in terms of patients and hospital care, little research has been conducted to outline its effects on medical staff. However, one qualitative study by Enguidanos et al. [29] conducted among physicians and nurses working in cooperation with PCTs found that PCT consultation services reduced the medical staff's burden and workload, allowing them to be faster and more efficient. In the present study, doctors in Korea asserted that the implementation of PCTs would likely improve difficulties they had experienced with administering palliative care to their patients.

In terms of the doctors' attitudes and expectations regarding the role of PCTs, those that stated "referring my patients to the hospice unit means I must give up on them," "referring my patients to the hospice unit causes them to lose hope," and "I only transfer my patients to the hospice unit upon impending death" were associated with positive attitudes towards hospice palliative care and tended to have higher expectations for PCTs. Doctors who expressed that "terminal care is my obligation" and "terminal care is a worthwhile activity" had negative attitudes towards hospice palliative care, although they appeared to have high expectations for PCTs. The present study indicated that most of the doctors did not regard health care services for terminal cancer patients or EOL care as their duty or a valuable effort. Instead, they tended to focus their patients' full recovery and the consumption of health care resources. According to another Korean study, the majority of health care providers $(67.2 \%)$ answered that they wished there was another doctor who could take care of their terminal cancer patients until death, and nearly half of them (45.3\%) did not provide any EOL care to such patients [17]. Meanwhile, previous studies have shown that doctors are significantly associated with both length of hospital stay and patient choices [30] at the point of referral to palliative care [31]. This suggests that, in terms of providing palliative care services at acute care centers, wider use of PCTs, and educating health care providers regarding their roles will help improve EOL for terminal cancer patients.

We found that several factors heightened expectations among doctors regarding the benefits of PCTs in caring for terminally-ill cancer patients; namely, female, denial that referring my patients to the hospice means I must give up on them, and lack of education regarding HPC. The notion that female doctors prefer PCTs more than male doctors was also reported by Roter and Hall [32], who found that female physicians show a better affinity for collaborative models of the patient-physician relationship than their male counterparts. Female physicians also tend to spend more time with their patients, are more likely to hold discussions regarding psychosocial context with their patients, and more often address feelings and emotions [32]. Therefore, female physicians would more likely place an emphasis on palliative care 
in the terminal care phase, including care for the dying patient, family care, and psychological and mental care, raising expectations for PCTs. In addition, individuals who were opposed to HPC because they feel it suggests they must give up on their patients showed lower expectations for PCTs. In our experience, PCTs can help doctors develop a caring attitude toward terminally ill patients; accordingly, curricula to cultivate related skills are needed in a variety of complementary medical settings.

Participants that did not agree with this notion expressed greater expectations for PCTs. As another study suggests, recognition and affirmation of the usefulness of HPC among doctors enables earlier palliative care intervention [33]. Thus, we assume that a positive attitude among doctors toward palliative care would further expand the role of PCTs in caring for terminally-ill cancer patients. Finally, physicians who had not received education regarding HPC reported greater expectations for PCTs than those who had received such education. This may be because, lacking sufficient training, they would face difficulties in caring for end-stage patients, which were recorded in our study. Thus, as part of a multiinterdisciplinary approach, PCTs may warrant a greater role in caring for terminally-ill cancer patients.

The strength of our study lies in that we surveyed a large number of doctors from different areas throughout Korea, targeting their experiences with palliative care. This allowed us to discern the likely roles of PCTs in meeting the palliative care needs of end-stage cancer patients in Korea. However, it is also necessary to discuss obstacles to the introduction of PCTs in Korea and tasks that await tackling based on the experiences of countries that have already introduced PCTs.

First, a protocol should be developed to facilitate referral to PCTs early in the course of treatment. Reville et al. [34] reported that patients were referred to PCTs at too late of a stage because they were not ready to receive palliative care services. They also reported that patients thought that palliative care could not be performed along with care aimed at prolonging their lives [33]. To provide quality care, referral to PCTs at appropriate times is very important, and a referral protocol that facilitates this should be developed.

Second, in acute care wards, patients should be helped to overcome their prejudice against palliative care so that become more accepting of it. A study conducted by Smith et al. [24] found that, since referral to PCTs could cause a psychological burden to patients and their families, doctors ended up referring their patients at later stages. In Korea, $24.0 \%$ of doctors responded that later referrals stemmed from a reluctance to tell their patients that they had terminal cancer [17]. In Taiwan, one study showed that more than $50 \%$ of all cancer patients did not clearly understand their terminal condition when consulting with hospital-based PCTs [35]. However, palliative care focuses on patient autonomy and respect for their free will. To resolve this clinical dilemma, hospital-based PCTs must assume a responsibility for assisting medical staff in communicating with the patient's family and building mutual trust to inform patients about their terminal illness [35].

Third, in all care settings, collaboration and open communication among medical staff are required. PCTs usually only visit a patient two or three times per week and are sometimes not able to communicate effectively with hospital staff [9]. Indeed, hospital-based PCT members often make up for a lack of conversation by writing notes in medical charts. Health professionals in acute hospital settings may often overlook these messages, resulting in mismanagement of any problems a patient may be experiencing $[21,35]$. To resolve communication issues, hospital-based PCTs and acute hospital wards should use the same standard assessment tools, hold regular meetings, and increase their frequency of visiting patients [9].

Fourth, for PCTs to provide quality services, institutions should provide sufficient human resources and training and hold meetings and educational seminars with doctors who request support [36,37]. In a Japanese study, $30 \%$ of all designated cancer hospitals in Japan reported that PCT consultation services were unavailable for more than $50 \%$ of the business hours on weekdays [8]. Another study found that job statements lacked sufficient detail on the required roles and activities of PCTs in palliative care [37]. To improve the activities of PCTs, we held educational workshops for an interdisciplinary team at the National Cancer Center [38]. However, standardized educational resources for training PCTs are needed in Korea, so that the delivery, development, and methods thereof are consistent.

Nevertheless, our study has a few limitations that warrant consideration. First, since the respondents comprised doctors in attendance at 10 conferences, we could not survey the opinions of those who were not present. Thus, the results may not sufficiently represent the opinions of all doctors in Korea. Second, the low response rate may suggest that those who participated in the survey were more interested in palliative care than those who refused, which may indicate the possibility of selection bias. Third, since the survey was administered as a self-report questionnaire, it was difficult to incorporate opinions about satisfaction with palliative care in clinical settings in which the respondents actually administered care. Future qualitative interview surveys should investigate the reasons why the reported needs failed to be met. Fourth, this survey included questions selected by research teams instead of those with validation scales; therefore, the validity and reliability of the questions might not be high. 


\section{Conclusion}

This study surveyed Korean doctors to examine unmet needs and satisfaction with palliative care services in Korea, as well as the expected benefits of PCTs. In doing so, we identified several patient- and physician-related aspects in which PCTs may be effective at improving palliative care. Future studies are needed to assess the relationship of costeffectiveness, patient and family quality of life, and doctor satisfaction with implementation of PCTs for early intervention in end-stage cancer patients.

\section{Conflicts of Interest}

Conflict of interest relevant to this article was not reported.

\section{Acknowledgments}

This study was supported by a grant from the National Cancer Center (grant number 1310241-3 \& 1611180-1), Republic of Korea. The funders had no role in study design, data collection and analysis, decision to publish, or preparation of the manuscript.

\section{References}

1. World Health Organization. Strengthening of palliative care as a component of integrated treatment throughout the life course. J Pain Palliat Care Pharmacother. 2014;28:130-4.

2. Weissman DE. Consultation in palliative medicine. Arch Intern Med. 1997;157:733-7.

3. Moine S. Improving access to specialist palliative care. BMJ. 2015;350:h1012.

4. Foreman T, Kekewich M, Landry J, Curran D. Impact of palliative care consultations on resource utilization in the final 48 to 72 hours of life at an acute care hospital in Ontario, Canada. J Palliat Care. 2015;31:69-75.

5. Bennett M, Corcoran G. The impact on community palliative care services of a hospital palliative care team. Palliat Med. 1994;8:237-44.

6. Erlenwein J, Geyer A, Schlink J, Petzke F, Nauck F, Alt-Epping B. Characteristics of a palliative care consultation service with a focus on pain in a German university hospital. BMC Palliat Care. 2014;13:45.

7. de Santiago A, Portela MA, Ramos L, Larumbe A, Urdiroz J, Martinez $\mathrm{M}$, et al. A new palliative care consultation team at the oncology department of a university hospital: an assessment of initial efficiency and effectiveness. Support Care Cancer. 2012;20:2199-203.

8. Nakazawa Y, Miyashita M, Morita T, Misawa T, Tsuneto S, Shima $\mathrm{Y}$. The current status and issues regarding hospitalbased specialized palliative care service in Japanese Regional Cancer Centers: a nationwide questionnaire survey. Jpn J Clin Oncol. 2012;42:432-41.

9. Kao CY, Hu WY, Chiu TY, Chen CY. Effects of the hospitalbased palliative care team on the care for cancer patients: an evaluation study. Int J Nurs Stud. 2014;51:226-35.

10. Morrison RS, Maroney-Galin C, Kralovec PD, Meier DE. The growth of palliative care programs in United States hospitals.
J Palliat Med. 2005;8:1127-34.

11. Jack B, Hillier V, Williams A, Oldham J. Hospital based palliative care teams improve the symptoms of cancer patients. Palliat Med. 2003;17:498-502.

12. Jack B, Hillier V, Williams A, Oldham J. Hospital based palliative care teams improve the insight of cancer patients into their disease. Palliat Med. 2004;18:46-52.

13. Manfredi PL, Morrison RS, Morris J, Goldhirsch SL, Carter JM, Meier DE. Palliative care consultations: how do they impact the care of hospitalized patients? J Pain Symptom Manage. 2000;20:166-73.

14. Gade G, Venohr I, Conner D, McGrady K, Beane J, Richardson $\mathrm{RH}$, et al. Impact of an inpatient palliative care team: a randomized control trial. J Palliat Med. 2008;11:180-90.

15. Morrison RS. Health care system factors affecting end-of-life care. J Palliat Med. 2005;8 Suppl 1:S79-87.

16. Sanders S, Bullock K, Broussard C. Exploring professional boundaries in end-of-life care: considerations for hospice social workers and other members of the team. J Soc Work End Life Palliat Care. 2012;8:10-28.

17. Lee JR, Lee JK, Hwang SJ, Kim JE, Chung JI, Kim SY. Doctor's perception and referral barriers toward palliative care for advanced cancer patients. Korean J Hosp Palliat Care. 2012;15: 10-7.

18. Jho HJ, Chang YJ, Song HY, Choi JY, Kim Y, Park EJ, et al. Perceived timeliness of referral to hospice palliative care among bereaved family members in Korea. Support Care Cancer. 2015;23:2805-11.

19. Yun YH, Kwon YC, Lee MK, Lee WJ, Jung KH, Do YR, et al. Experiences and attitudes of patients with terminal cancer and their family caregivers toward the disclosure of terminal illness. J Clin Oncol. 2010;28:1950-7.

20. Kim JH, Kim Y, Park JN. Hospice care trends and reform in 
US. Korean J Hosp Palliat Care. 2011;14:1-7.

21. Morita T, Akechi T, Ikenaga M, Kizawa Y, Kohara H, Mukaiyama T, et al. Late referrals to specialized palliative care service in Japan. J Clin Oncol. 2005;23:2637-44.

22. Morita T, Miyashita M, Tsuneto S, Sato K, Shima Y. Late referrals to palliative care units in Japan: nationwide followup survey and effects of palliative care team involvement after the Cancer Control Act. J Pain Symptom Manage. 2009;38: 191-6.

23. Yang GM, Ewing G, Booth S. What is the role of specialist palliative care in an acute hospital setting? A qualitative study exploring views of patients and carers. Palliat Med. 2012;26: 1011-7.

24. Smith TJ, Coyne PJ, Cassel JB. Practical guidelines for developing new palliative care services: resource management. Ann Oncol. 2012;23 Suppl 3:70-5.

25. Kamal AH, Swetz KM, Carey EC, Cheville AL, Liu H, Ruegg SR, et al. Palliative care consultations in patients with cancer: a mayo clinic 5-year review. J Oncol Pract. 2011;7:48-53.

26. Ludke RL, Smucker DR. Racial differences in the willingness to use hospice services. J Palliat Med. 2007;10:1329-37.

27. Pantilat SZ, O'Riordan DL, Dibble SL, Landefeld CS. Hospital-based palliative medicine consultation: a randomized controlled trial. Arch Intern Med. 2010;170:2038-40.

28. Rabow MW, Dibble SL, Pantilat SZ, McPhee SJ. The comprehensive care team: a controlled trial of outpatient palliative medicine consultation. Arch Intern Med. 2004;164:83-91.

29. Enguidanos S, Housen P, Goldstein R, Vesper E, Allen J, Braun W. Physician and nurse perceptions of a new inpatient palliative care consultation project: implications for education and training. J Palliat Med. 2009;12:1137-42.

30. Lamont EB, Christakis NA. Physician factors in the timing of cancer patient referral to hospice palliative care. Cancer. 2002;94:2733-7.

31. Wentlandt K, Krzyzanowska MK, Swami N, Rodin GM, Le LW, Zimmermann C. Referral practices of oncologists to specialized palliative care. J Clin Oncol. 2012;30:4380-6.

32. Roter DL, Hall JA. Why physician gender matters in shaping the physician-patient relationship. J Womens Health. 1998;7: 1093-7.

33. Johnson CE, Girgis A, Paul CL, Currow DC. Cancer specialists' palliative care referral practices and perceptions: results of a national survey. Palliat Med. 2008;22:51-7.

34. Reville B, Miller MN, Toner RW, Reifsnyder J. End-of-life care for hospitalized patients with lung cancer: utilization of a palliative care service. J Palliat Med. 2010;13:1261-6.

35. Hsu TH, Hsiao SC, Koong SI, Lai YL, Lai ML, Chen CY. The performance of Taiwan hospice share-care project in 2005. Taiwan J Hosp Palliat Care. 2007;12:129-42.

36. Rabow MW, Petersen J, Schanche K, Dibble SL, McPhee SJ. The comprehensive care team: a description of a controlled trial of care at the beginning of the end of life. J Palliat Med. 2003;6:489-99.

37. Luthi FT, Cantin B. The complex role of a palliative care consultant in a tertiary hospital: can a practice model help in this wild world? J Palliat Med. 2010;13:1178-81.

38. Nakazawa Y, Kizawa Y, Hashizume T, Morita T, Sasahara T, Miyashita M. One-year follow-up of an educational intervention for palliative care consultation teams. Jpn J Clin Oncol. 2014;44:172-9. 